\title{
MULTIMODALIDADE E GÊNERO SOCIAL NA PUBLICIDADE: REPRESENTAÇÕES DE DIVERSIDADE EM ANÚNCIOS
}

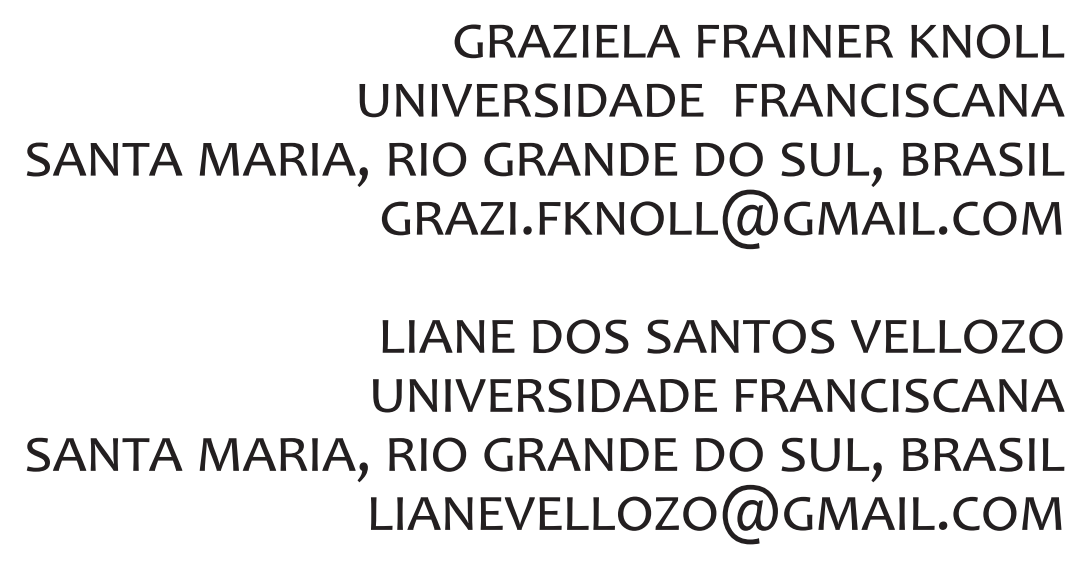




\section{MULTIMODALIDADE E GÊNERO SOCIAL NA PUBLICIDADE: REPRE- SENTAÇÕES DE DIVERSIDADE EM ANÚNCIOS}

Resumo: $O$ objetivo deste trabalho é analisar a multimodalidade em anúncios publicitários, com foco nas construções identitárias. Para tanto, foram escolhidas três peças publicitárias dos anunciantes Benetton, Airbnb e Skol, por sua aparente diversidade de representações humanas. A análise multimodal dos textos foi feita a partir da Gramática do Design Visual de Kress e van Leeuwen (2006).

Palavras-chave: Multimodalidade. Publicidade. Gênero. Linguagem. Diversidade.

\section{MULTIMODALIDAD Y GÉNERO SOCIAL EN PUBLICIDAD: REPRESEN- TACIONES DE DIVERSIDAD EN ANUNCIOS}

Resumen: El objetivo de este trabajo es analizar la multimodalidad en anuncios publicitarios, con foco en las construcciones identitarias. Para ello, se eligieron tres piezas publicitarias de los anunciantes Benetton, Airbnb y Skol, por contener aparente diversidad de representaciones humanas. El análisis multimodal de los textos se hará a partir de la gramática del diseño visual de Kress y van Leeuwen (2006).

Palabras clave: Multimodalidad. Publicidad. Género. Idioma. Diversidad.

\section{MULTIMODALITY AND GENDER IN ADVERTISING: DIVERSITY RE- PRESENTATIONS IN ADVERTISEMENTS}

Abstract: The aim of this work is to analyze the multimodality in advertisements, focusing on identity constructions. In order to do so, three advertising pieces were chosen from the advertisers Benetton, Airbnb and Skol, because they contain an apparent diversity of human representations. The multimodal analysis of the texts was made from the Visual Design Grammar of Kress and van Leeuwen (2006).

Keywords: Multimodality. Advertising. Gender. Language. Diversity. 


\section{INTRODUÇÃO}

Por constituírem parte da cultura, as identidades dependem de práticas de significação, tanto que, segundo Hall (1999) ressalta, são construtos culturalmente estabelecidos e que se modificam conforme o contexto social, variando ao longo da vida. Como elemento da identidade social, o gênero é uma construção cultural também mutável, que se constitui como uma divisão básica de poder e, dessa forma, seu estudo deve estar ligado ao contexto social e histórico, para serem compreendidos os papéis sociais que são gerados a partir dos gêneros (SCOTT, 1995).

Os discursos de gênero presentes nas práticas midiatizadas como a publicidade atuam no sentido de que, segundo Vestergaard e Schroder (2010, p. 74), "os anúncios devem preencher a carência de identidade de cada leitor, a necessidade que cada pessoa tem de aderir a valores e estilos de vida", realizando um elo de ligação entre identidade e consumo. Desse modo, a publicidade será analisada sob um ângulo de contextualização social, em que ideologias serão discutidas a partir das representações encontradas na linguagem.

A partir desse entendimento, este trabalho ${ }^{1}$ tem como objetivo analisar a multimodalidade em anúncios publicitários com foco nas construções identitárias presentes em peças publicitárias dos seguintes anunciantes: Benetton, Airbnb e Skol. As peças foram selecionadas por apresentarem aparente diversidade de representações humanas, o que está relacionado ao conceito das campanhas, conforme será averiguado a partir dos resultados encontrados.

A análise multimodal dos anúncios será feita à luz da Gramática do Design Visual de Kress e van Leeuwen (2006), que fornece um conjunto de categorias próprias para o estudo das imagens. Por entender que as imagens são tão importantes quanto a linguagem verbal para a significação de textos e discursos, a análise multimodal contribui para a desnaturalização com que geralmente é tratada a leitura de imagens. As categorias visuais, tais como processos conceituais, saliência e valor da informação, entre outras, podem reforçar, contrapor, contrastar, destacar ou complementar o que é verbalmente expresso em um anúncio publicitário, como será investigado

$1 \quad$ O presente estudo integra um projeto de pesquisa PROBIC/UFN que tem como objetivo investigar discursos de gênero contra-hegemônicos na publicidade por meio da análise crítica do discurso e da multimodalidade. 
na linguagem.

Assim, o embasamento teórico da pesquisa é a análise crítica do discurso, a qual propicia a compreensão de fenômenos socioculturais ao evidenciar as representações na linguagem. A relevância da pesquisa deve-se à compreensão dos significados que são encontrados na linguagem de anúncios publicitários que exploram a diversidade de identidades, inclusive identidades de gênero, na sua temática.

\section{IDENTIDADE E GÊNERO}

A identidade foi, por muito tempo, tratada como um elemento imutável e inquestionável na vida dos indivíduos. Na modernidade tardia e na pós-modernidade, em contraposição, começaram a se destacar as teorias culturalistas que interpretam as identidades como um processo amplo de mudanças em que se deslocam estruturas sociais, a partir de uma premissa que Hall (1999) coloca como a crise de identidade do sujeito, ou seja, a perda do sentido de si e o descentramento dos indivíduos do seu lugar no mundo social e cultural, um processo fortalecido pela globalização e pelos movimentos sociais.

Segundo Hall (1999), a questão da identidade pode ser entendida por meio de três concepções iniciais: o sujeito do lluminismo como um sujeito centrado e unificado; o sujeito sociológico como um sujeito formado com relação a outras pessoas importantes em seu contexto social, com forte influência cultural; e o sujeito pós-moderno, que não possui uma identidade fixa, essencial ou permanente. Dentre os movimentos sociais, o feminismo colaborou para o descentramento da identidade do sujeito, indo além de um movimento político e levantando questionamentos sobre espaço público e privado, evidenciando os lugares ocupados pelas mulheres historicamente.

Ocorre que os lugares ocupados pelas mulheres ao longo da história, por muito tempo, foram justificados pelo argumento biológico. Segundo Bourdieu (2005) explica, a análise biológica do corpo humano levou a interpretações que responderam a inúmeros questionamentos, tais como a inserção do homem em atividades de mão-de-obra, que se deu pela nomeação do falo como "máquina”, ou seja, apenas o possuidor dela é capaz de desenvolver atividades que envolvam manuseio de ferramentas, enquanto às mulheres foi designado o papel de permanecer no lar, à espera dos homens. Entretanto, o autor afirma que a interpretação da biologia corporal já é uma construção cultural, pois a partir do argumento biológico se criaram cate- 
gorizações que, no decorrer da evolução das mulheres e dos homens, se tornaram questionáveis, pois serviam ao propósito de justificar a dominação masculina mais do que a qualquer outra razão.

Dessa forma, o androcentrismo possibilitou, além da inserção do homem nos sistemas que regiam a colheita e a guerra, a segregação das mulheres de atividades sociais e de convivência, ao passo que as tarefas destinadas a elas as mantinham nos espaços privados, como o cuidado com o jardim e o armazenamento de leite, além do cuidado dos filhos, como explica Colling (2004). A autora também afirma que, por meio de teorias sobre afetividade e reprodução ligadas à feminilidade, se justificava certa destinação ao silêncio e à obscuridade. Como reflexo disso, o espaço público foi, por muito tempo, um privilégio exclusivo dos homens, já que os valores e normas de conduta se deram por meio de referências androcêntricas que definiam o homem como uma figura de virilidade, construída diante de outros homens, enquanto a mulher era construída como uma figura de feminilidade, em espaços restritos e domésticos.

Isso representa uma violência simbólica, a qual, por vezes, segundo Bourdieu (2005), acaba por minimizar a violência física, esquecendo-se dos espancamentos e abusos. Essa força se encontra na reprodução de discursos de dominação pelos dominados, legitimando-a. Nessas estruturas de dominação, o autor acrescenta, além da própria figura masculina à frente da família, todas as instituições sociais existentes, dentre elas: a Igreja, as escolas e o próprio Estado. Essas estruturas de formação social são, portanto, estruturadas sob influência do patriarcado, sendo expressas de maneiras que justificam a desigualdade (BOURDIEU, 2005; COLLING, 2004).

A violência simbólica se fortalece, também, nas relações que os dominados estabelecem entre si, à medida que há mulheres que acabam disseminando o consentimento sobre a violência sofrida, tornando-se adeptas do mesmo discurso por julgá-lo naturalizado. Esse aspecto é problemático porque, segundo Taylor (2010), a identidade de cada pessoa é influenciada, em grande parte, pela projeção dos outros, ou seja, uma pessoa se reconhece também com base nas opiniões emitidas por seus entes próximos, daí, a importância das relações familiares nesse processo.

Para compreender a identidade e os papéis diferentes destinados a um e a outro sexo com a finalidade de aprofundar a crítica, Colling (2004) ressalta que é imprescindível incluir como categorias de análise questões de classe e raça (ou, atualizando o conceito da autora, etnia), pois essas diferenças 
causam, no passado e no presente, grandes interferências na compreensão do gênero e das relações sociais. A configuração dos sujeitos, no que diz respeito gênero, possui simbolismos que fazem parte dos discursos que circulam, levando em consideração que o sexo feminino se originou de uma categorização biológica mas não é levado a sério como tal. A natureza foi, durante muito tempo, a principal justificativa para a diferenciação dos sujeitos femininos e masculinos, sendo a mulher considerada uma extensão do masculino.

Ainda segundo Colling (2004), a proposta de uma igualdade entre as pessoas diz respeito a seus direitos civis e políticos e não à sua condição na sociedade. A divisão entre os sexos não propõe uma hierarquização, mas sim uma maneira de estar no mundo, enquanto o gênero é considerado uma categoria analítica que facilita a compreensão de uma condição social de hierarquização entre masculino e qualquer outro gênero.

Como mecanismos de perpetuação das relações de gênero e identificações presentes no senso comum, a publicidade produz discursos de gênero que afetam as opiniões socialmente compartilhadas. Assim, esses discursos possuem forte influência na mídia e na vida das pessoas, pois fazem parte do cotidiano e contribuem para a construção do senso comum. Nesse sentido, a linguagem não só serve como testemunho de visões de mundo, mas também reproduz, de certa forma, a realidade da sociedade. O papel da publicidade como propagadora de estilos de vida acaba por assumir a manutenção, ou seja, atualiza o público sobre tendências de comportamento e atitudes (VESTERGAARD; SCHRODER, 2010).

A construção de identidades pode ser analisada também na indústria dos brinquedos, os quais, segundo Caldas-Coulthard e van Leeuwen (2004), são objetos semióticos que carregam potenciais significados em imagens e textualidades no âmbito social pois seu design transmite mensagens sobre práticas sociais. Os brinquedos comunicam valores e significados e estão divididos, geralmente, em duas categorias: para meninas, caracterizados pela cor rosa, e para meninos, frequentemente na cor azul. Dessa forma, os brinquedos materializam e reproduzem uma realidade específica, porém em escala menor, como uma visualização da vida adulta que, tal como outras vivências, segue padrões estereotipados. Os autores constatam, por exemplo, que os brinquedos denominados masculinos possuem articulações, movimento e estabilidade ao ficar em pé, além de serem contextualizados em espaços de ação, segurando objetos e propondo aventuras. Em 
contraponto, os brinquedos sinalizados como femininos só se estabilizam dentro da embalagem, pois fora dela a estrutura não se mantém em pé, e as caixas e acessórios normalmente possuem temas ligados ao ambiente doméstico, além de a estética das bonecas representar mulheres jovens ou, inclusive, crianças.

De modo semelhante, a publicidade, com suas imagens, reproduz frequentemente identidades persistentes no senso comum, ainda que a construção da imagem feminina passe, recentemente, por um processo de mudanças, já que o empoderamento e os discursos de ascensão feminina estão em voga em contextos variados, como no âmbito de trabalho e nas mídias sociais. Porém, ainda é possível observar traços de uma cristalização de características do passado, as quais reforçam alguns estereótipos conservadores da sociedade. Como exemplo, no início dos anos 2000, a análise de Ghilardi-Lucena (2003) do anúncio de um site que utilizava como referência criativa a música "Ai, que saudades da Amélia" de Ataulfo Alves e Mário Lago, reforçava o estereótipo da mulher que cuidava do lar e era submissa ao seu companheiro, imagem que foi atualizada para vender uma plataforma virtual de serviços ligados aos cuidados do lar e dos filhos. A redação da campanha fazia uso da letra da canção, porém com alterações:

Amélia era tão competente que criou uma empresa enorme.

Chegou o maior site de soluções para o lar,

amelia.com.br

Amélia, que era mulher de verdade, agora virou virtual.

Amélia.com.br chegou para ajudar você nos serviços de casa.

Amélia faz compras de supermercado, eletrodomésticos, dá dicas de culinária, nutrição, jardinagem, ajuda a contratar mão-de-obra, a cuidar dos filhos e muito mais. E, toda (Transcrição de anúncio publicado na revista Veja, 17-05-2000, citado por Guilardi-Lucena, 2003).

Sobre o consumo dessas publicidades, deve-se considerar que, não sendo percebidas as estratégias de manipulação utilizadas na sua produção, podem culminar na assimilação do discurso midiatizado e na manutenção de padrões há muito tempo presentes no senso comum, que se chocam inclusive com os novos discursos de empoderamento feminino. Já a representação da figura masculina nos anúncios, em contraponto à feminina, 
segundo Ghilardi-Lucena (2003), é caracterizada por razão, força, objetividade e ciência. Esses valores que enfatizam as diferenças de gênero estão presentes em uma propaganda da Nestlé analisada pela autora, anúncio em que a figura materna aparece preocupada com alimentação de seu bebê, como a principal responsável por essa tarefa, enquanto o pai se mostra preocupado com a carreira profissional do filho que segura no colo na respectiva imagem. Além disso, ambos os atores estão posicionados em cenários diferentes: a mulher é localizada em uma cozinha, e o homem em um pátio, remetendo à dicotomia privado e

Nessa direção, é importante destacar que os modelos de consumo e as identificações sugeridas pela mídia, frequentemente, possuem como base os estereótipos, ou seja, falsas construções da realidade que são resultados de generalizações e de associações de comportamento e valores, como por exemplo, a representação da mulher como mãe e zeladora do lar. Conforme afirmam Lakatos e Marconi:

Os estereótipos baseiam-se em características não comprovadas e nao demonstradas, atribuídas a pessoas, coisas e situações sociais, mas que, na realidade, não existem. Os principais estereótipos referem-se a classe, etnia e religião. Pelo fato de um estereótipo salientar qualidades em vez de defeitos, não significa que deixe de ser estereótipo. (LAKATOS; MARCONI, 1990, p. 106).

Conforme afirma Knoll (2018), a importância dos discursos de identidade na mídia é proporcional à relevância da cultura, pois a mídia pode ser situada em meio às instituições culturais, já que é difusora de bens, produtos culturais, meios e locais para práticas sociais.

Dessa forma, a cultura que a mídia produz ou reproduz é fundamentada no consumo, e as identidades se encontram formuladas e definidas para constituir esses modelos que favorecem a identificação entre produtos e consumidores, processo em que a linguagem desempenha papel basilar. Ainda, a fim de abordar estudos sobre identidade de gênero, cabe fazer um recorte teórico que inclui, pelo menos, quatro pesquisadoras que tiveram uma contribuição histórica para esse campo de estudos: Rubin (1975), Perrot (2007), Scott (1995) e Lauretis (1994). Perrot (2007), no seu amplo estudo sobre a história das mulheres, enfatiza que o desenvolvimento do gênero rumo à emancipação e ao questionamento dos papéis e lugares distintos 
ocupados por mulheres e homens ao longo da história, foi acompanhado de certo silenciamento a respeito da participação feminina, primeiro restrita ao espaço privado e, após, alcançando o espaço público. Dessa forma, o questionamento dos papéis atribuídos na divisão binária da sociedade patriarcal ocidental foi acompanhado da inserção das mulheres no espaço público das guerras, das praças, das cidades, da política e, principalmente, sua inserção no trabalho. Os tensionamentos ocasionados com essas conquistas não passaram despercebidos, pelo contrário, os embates ideológicos, frequentemente, resultaram em ações de violência e repressão contra as mulheres (PERROT, 2007).

Para a superação dessas desigualdades e embates, foi fundamental o desenvolvimento da civilização, à medida que mais direitos são alcançados e restrições são contestadas. Porém, também com frequência, são retomadas as disputas por poder sobre os corpos alheios, "com a tranquila segurança do direito de poder dispor livremente do corpo do outro, este corpo que lhe pertence" (PERROT, 2007, p. 454).

O gênero como conceito relacional foi introduzido pelos estudos de Rubin (1975), seguindo a corrente feminista e marxista francesa, que o definiu como um sistema que demarca as diferenças da condição sexual, isto é, "um conjunto de arranjos pelo qual a sociedade transforma a sexualidade biológica em produto da atividade humana" (RUBIN, 1975, s.n.). Para a pesquisadora, esse é um sistema sexo-gênero que visa assegurar a domesticação feminina e, ao mesmo tempo, garante a reprodução de uma economia política do sexo. Dessa forma, enfatiza, de modo pioneiro, que a opressão das mulheres estaria relacionada não ao corpo biológico, mas a sistemas sociais, que incluem desde o parentesco entre as pessoas - uma vez que eram os homens da família que decidiam criar laços sociais, e as muIheres eram utilizadas como meio de troca - até estruturas mais elaboradas presentes na sociedade.

Para o reconhecimento do campo de estudos de gênero, também foi necessária certa superação da noção de que gênero era sinônimo de estudos sobre mulheres ou para mulheres e, para tanto, foi de extrema relevância o trabalho de Scott (1995, p. 71-72) sobre gênero como "uma categoria útil de análise histórica", ou seja, uma categoria que, no sentido mais literal, constitui "uma maneira de se referir à organização social da relação entre os sexos", conforme expressa a autora. Segundo explica, o uso do termo nos anos 80, data de publicação do seu texto basilar, ainda estava atrelado 
aos estudos de feministas americanas a fim de enfatizar as relações sociais envolvidas nas distinções de sexo, isto é, como forma de negar qualquer argumento biológico, uma etapa, sem dúvida, importante para os estudos feministas, mas ainda uma compreensão um pouco restrita do conceito. Após, estudiosas e estudiosos passaram a propor o estudo integrado de três tipos de relações, gênero, raça e classe: "o interesse pelas categorias de classe, de raça e de gênero assinalava, em primeiro lugar, o envolvimento do a pesquisador/a com uma história que incluía as narrativas dos/as oprimidos/as e uma análise do sentido e da natureza de sua opressão" (SCOTT, 1995, p. 73).

Entretanto, a autora ressalta que o problema nesse caso é que o uso dessas três categorias atreladas indica uma paridade entre os termos que, na realidade, não existe, já que a categoria de classe, por se fundamentar em teorias econômicas, é bem mais definida e rígida do que as demais, de difícil definição, como raça ou gênero. Assim, a emergência do gênero como uma categoria de análise histórica de processos sociais aconteceu no fim do século XX, quando historiadoras e historiadores perceberam a necessidade de ampliar os debates para além da oposição binária feminino/masculino (SCOTT, 1995).

Prosseguindo com os estudos de gênero, a contribuição de Lauretis (1994) está na elaboração do conceito de gênero como uma tecnologia que se diferencia da diferença sexual. Segundo Lauretis (1994, p. 2), o feminismo instituiu "uma nova maneira de pensar sobre a cultura, sobre a linguagem, a arte, a experiência e o próprio conhecimento", à medida que redefiniu e ampliou o debate político, incluindo questões antes consideradas pessoais na agenda político-social das pessoas.

Dessa forma, o gênero é proposto pela autora como representação e auto-representação, como produto de diferentes tecnologias sociais que se encontram nas práticas institucionalizadas e na vida cotidiana. Nesse sentido, o gênero "é a representação de uma relação, a relação de pertencer a uma classe, um grupo, uma categoria" (LAURETIS, 1994, p. 210), com a ressalva de que, nesse caso, a classe refere-se à categorização de pessoas e entidades, e não a uma classificação socioeconômica. Consequentemente, o gênero é, ao mesmo tempo, um produto e um processo de práticas de representação e auto-representação, pois constrói relações entre um sujeito e outros sujeitos previamente constituídos como uma classe.

Por ser uma tecnologia, essa é "uma construção sociocultural” e, ao mesmo tempo, "um aparato semiótico", pois “o fato de alguém ser re- 
presentado ou se representar como masculino ou feminino subentende a totalidade daqueles atributos sociais" (LAURETIS, 1994, p. 212). Segundo explica, a construção do gênero depende de várias tecnologias do gênero (p. ex., o cinema) e discursos institucionais (p. ex., a teoria) com poder de controlar o campo do significado social e assim produzir, promover e 'implantar' representações de gênero" (LAURETIS, 1994, p. 228). No entanto, é também por ser uma tecnologia, um processo e um produto de práticas de representação que o gênero pode ter suas construções hegemônicas desconstruídas e reelaboradas.

\section{ANÁLISE CRÍTICA DO DISCURSO E MULTIMODALIDADE}

A análise crítica do discurso (ACD) tem como premissa a definição de linguagem como prática social (FAIRCLOUGH, 2001; WODAK, 2004), de maneira que linguagem e relações de poder se vinculam em contextos políticos, midiáticos, culturais, institucionais, entre outros, mediante o discurso. Por esse viés, a análise não contempla apenas a materialidade dos textos verbalizados, orais ou escritos, pelo contrário, como o objeto investigativo é amplo, é possível que seja feita uma descrição dos processos sociais que levam à produção dos discursos pelos sujeitos envolvidos, e o significado que suas interações produzem a partir dos textos no contexto social (FAIRCLOUGH, 2001).

A mídia se contitui como um espaço de disputas de poder mediante o discurso, pois, segundo Wodak (2004), enquanto instituição social, o discurso como instrumento de poder e como instrumento de construção social, portanto, não existe sem o discurso. Também é relevante compreender os discursos que prevalecem ou são melhor avaliados perante determinados grupos, pois a linguagem, os costumes e as percepções são construídas sob outros pontos de vista, que nem sempre coincidem com os pontos de vista dos produtores.

Conforme Fairclough (2001), o discurso é organizado em três dimensões: o texto, a prática discursiva e prática social. O texto é a materialização do discurso de forma linguística ou, por exemplo, verbo-visual; a prática discursiva envolve a distribuição e o consumo dos textos; e a prática social se encontra ligada ao contexto da realização discursiva, com suas orientações culturais e ideológicas que acabam compondo o discurso.

Para analisar a materialidade discursiva, isto é, o texto, Kress e van Leeuwen (2006) elaboraram a Gramática do Design Visual ([1996], 2006). Se- 
gundo os autores, uma imagem deve ser estudada como um sistema semiótico que comunica significados e que funciona de modo autônomo, como imagem, ou de forma combinada com um texto verbal. Uma multiplicidade de recursos semióticos está à disposição e em foco nas mensagens produzidas. Assim, a multimodalidade define-se como a característica dos textos que utilizam mais de um código semiótico, lembrando que "escrever é por si só uma forma de comunicação visual”, devido à tipografia e às cores utilizadas no texto escrito (KRESS; van LEEUWEN, 2006, p. 17).

Além disso, as tecnologias da informação e da comunicação ao alcance de diversos usuários contribui para a multiplicação dos discursos multimodais na mídia. Cabe ressaltar que a mídia costuma utilizar textos multimodais exatamente para ampliar o alcance e as possibilidades de significação de suas mensagens, as quais se tornam persuasivas ao público (KNOLL, 2018). Kress e van Leeuwen (2006) consideram que os discursos multimodais atendem ao foco capitalista de produção e consumo que a mídia segue, já que potencializa a produção de sentidos, não restritos a somente um código sígnico. Assim, a estética é supervalorizada em sociedades nas quais os discursos multimodais e midiáticos se fazem presentes.

Com a Gramática do Design Visual, Kress e van Leeuwen (2006) forneceram aos estudos da linguagem um conjunto de categorias e opções de análise de textos multimodais. Essa gramática tem como base a Gramática Sistêmico-Funcional de Halliday (1985), e os significados se ligam às diferentes funções da linguagem: a metafunção representacional refere-se ao modo como se organizam as experiências de mundo na linguagem; a metafunção interativa se refere ao modo como os sujeitos interagentes se relacionam socialmente por meio da linguagem; já a metafunção composicional corresponde aos modos de organização do texto.

Kress e Van Leeuwen (2006) afirmam que as escolhas feitas para a composição visual das imagens em determinado contexto de comunicação resultam na formação de redes de significados que se referem: ao conteúdo e às experiências que são representadas na linguagem; às relações interpessoais que se estabelecem entre os interlocutores e desses com as representações; ao modo como o texto é organizado em sua unidade semântica. Consequentemente, as metafunções ocorrem simultaneamente, contudo, em um texto multimodal, uma função da linguagem pode predominar em relação às outras. Para cada metafunção há um conjunto de categorias multimodais que podem ser descritas, conforme será visto nas análises dos 
anúncios.

\section{ANÁLISE DOS ANÚNCIOS: REPRESENTAÇÕES IDENTITÁRIAS NA PUBLICIDADE}

Para contextualização da prática social e discursiva realizada, os anúncios materializam a publicidade de produtos e serviços distribuídos mundialmente, porém, dirigidos ao público brasileiro em apenas um dos casos e mundial em dois dos anúncios, escritos em inglês. Todas as peças foram veiculadas na internet, em blog e sites de rede social dos respectivos anunciantes. O público, nesse caso, não pode ser contabilizado ou particularizado, pois se refere a milhões de seguidores e usuários de internet, o que ampliado conforme a divulgação das campanhas em sites de marketing e jornais que enfatizaram os discursos inovadores e rompedores de estereótipos, como demonstram os casos dos anúncios de Skol, comentado pelo jornal O Sul, Benetton, comentado por um site italiano e Airbnb, comentado por um site de marketing digital como uma das principais campanhas de 2017 para mídias sociais.

As categorias de análise multimodal utilizadas abrangem as metafunções representacional, interativa e composicional de acordo com Kress e van Leeuwen (2006), categorias que estão apresentadas e definidas no Quadro 1.

\begin{tabular}{|l|l|}
\hline GDV (Kress; van Leeuwen, 2006) & Categoria e definição \\
\hline Metafunção representacional & $\begin{array}{l}\text { Processos conceituais: descrevem a im- } \\
\text { agem em modos de ser, ou seja, o foco } \\
\text { das imagens não é uma ação realizada, } \\
\text { mas a forma de representar o ator. }\end{array}$ \\
\hline Metafunção interativa & $\begin{array}{l}\text {-Contato (oferta ou demanda) - como } \\
\text { oferta, a representação do ator é de } \\
\text { forma estática, posicionado com um } \\
\text { produto a ser apresentado ao especta- } \\
\text { dor; já como demanda, consideram-se } \\
\text { os vetores (linhas) que partem do olhar } \\
\text { do ator representado na imagem. } \\
\text {-Distância social - representação do } \\
\text { ator em plano fechado ou plano aber- } \\
\text { to). } \\
\text {-Perspectiva - ângulo da fotografia } \\
\text { (frontal, oblíquo ou vertical). }\end{array}$ \\
\hline
\end{tabular}




\begin{tabular}{|l|l|}
\hline Metafunção composicional & $\begin{array}{l}\text {-Enquadramento - existência ou não de } \\
\text { molduras na imagem. }\end{array}$ \\
& $\begin{array}{l}\text {-Saliência - hierarquia, tamanho, cores } \\
\text { e posicionamento de atores e objetos. } \\
\text {-Valor da informação - posicionamento } \\
\text { dos atores e objetos a partir de cen- } \\
\text { tro e margem da imagem (dividindo a } \\
\text { imagem verticalmente, tem-se o dado } \\
\text { à esquerda e o novo à direita; dividindo } \\
\text { a imagem horizontalmente, tem-se o } \\
\text { ideal no topo e o real na base da ima- } \\
\text { gem). De modo geral, como valor da } \\
\text { informação, ganham mais destaque o } \\
\text { elementos situados à direita (novo) e } \\
\text { no topo (ideal) da imagem. }\end{array}$ \\
\hline
\end{tabular}

Quadro 1 - Categorias de análise

Fonte: Elaborado pelas autoras.

$\mathrm{Na}$ análise da metafunção representacional, foram encontrados processos conceituais nas imagens dos três anúncios: no primeiro anúncio ( $\mathrm{A} 1$, Benetton), foi encontrado processo conceitual classificatório de taxonomia implícita; no segundo (A2, Skol), foi encontrado processo conceitual classificatório; e no terceiro anúncio (A3, Airbnb), foi encontrado processo conceitual analítico.

A primeira imagem (Figura 1) mostra um conjunto de pessoas jovens, de diferentes sexos, com diferentes cores de pele e de cabelos, de diferentes etnias abraçadas em contraste com um fundo branco. No canto inferior direito se localiza um retângulo verde com o nome da campanha United Colors of Benetton.

Figura 1: Anúncio de Benetton.

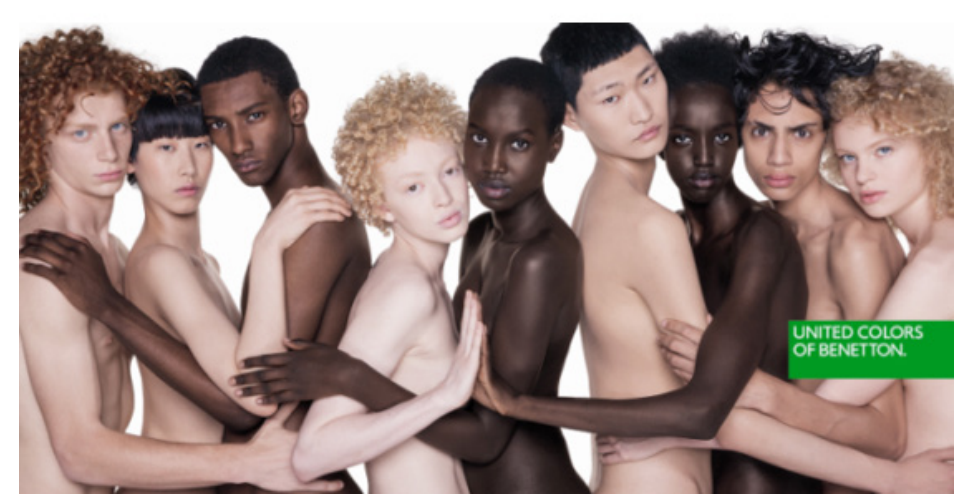

Fonte: Trevisotoday (2018). 
O processo conceitual classificatório se justifica porque as pessoas estão representadas caracterizando um grande agrupamento, e o foco da imagem não é uma ação específica, mas o fato de estarem todos misturados e abraçados. É interessante observar que estão todos aparentemente sem roupa, o que pode significar estar livre de rótulos e vestir a própria pele. A taxonomia é implícita porque ainda que todos estejam fotografados nas mesmas condições e no mesmo plano médio, percebe-se que as pessoas formam três agrupamentos menores, o da esquerda com três pessoas, o do centro com duas e o da direita com quatro. Houve o cuidado na direção de arte da foto de incluir em cada um desses três agrupamentos uma pessoa de pele escura (afrodescendente). As pessoas dos três grupos se abraçam entre si e ao mesmo tempo tocam as pessoas do grupo ao lado.

A segunda imagem (Figura 2) mostra três pessoas jovens com diferentes cores de pele e cabelo, sendo uma delas com vitiligo², abraçadas em contraste com o fundo marrom. No canto superior direito se localiza o logotipo da marca Skol em branco. O processo conceitual classificatório se justifica porque as pessoas caracterizam um grupo em que o ator central abraça sobre os ombros ambas as mulheres.

Figura 2: Anúncio de Skol.

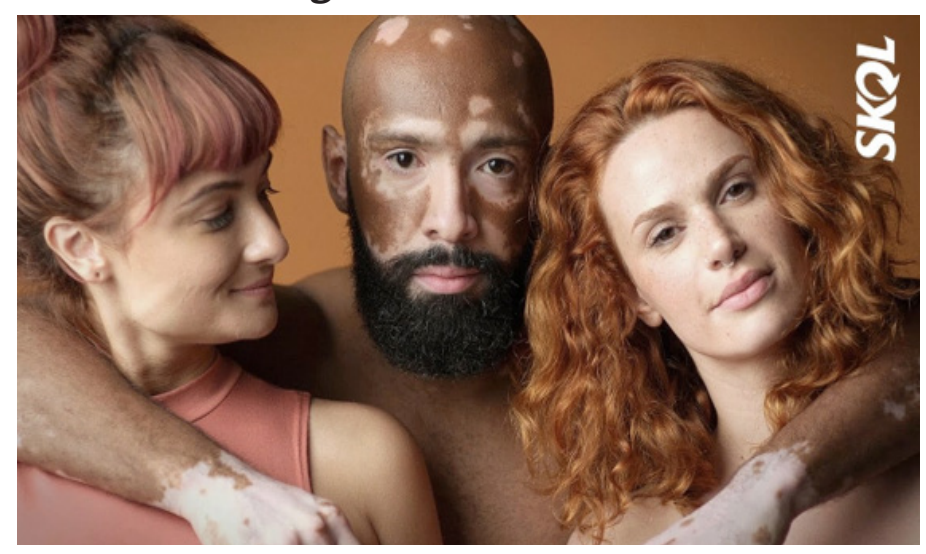

Fonte: O Sul (2017).

A terceira imagem (Figura 3) forma um mosaico de rostos de pessoas, também com diversidade de cores de pele e de cabelos, além de diversidade de idades. No canto inferior direito se localiza o nome da campanha \#weaccept e o logotipo da marca sob um fundo vermelho alaranjado. Sobre cada rosto, são lidas as seguintes frases: No matter, who you are, where you're

2 Vitiligo é uma doença que se caracteriza pela perda de coloração da pele em lesões (SBD, 2018, online). 
from, who you love, or who you worship, we all belong, the world is, more beautiful, the more you, accept.

Figura 3: Anúncio Airbnb.

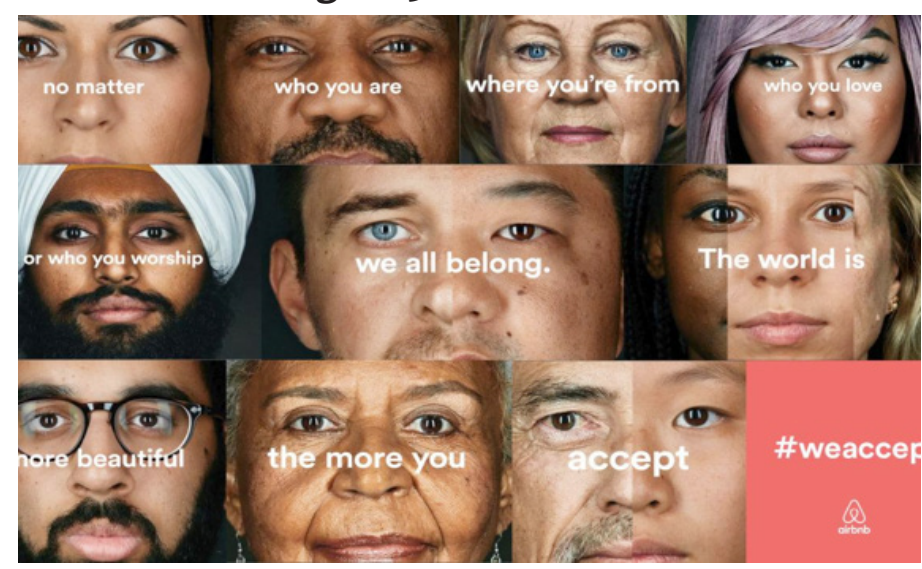

Fonte: Escalate Digital Marketing (2017).

O processo conceitual analítico se caracteriza pela representação de fragmentos do rosto de pessoas que unidos formam cada rosto. Verifica-se isso em enquadramentos da segunda e da terceira linha do anúncio, em que há rostos formados com a lateral e principalmente os olhos de pessoas diferentes. Ao segmentar a imagem do rosto, o anúncio realiza o processo analítico, que dá mais enfoque às partes da imagem do que ao todo. Ainda assim, todos os rostos se encontram na mesma tela ou página.

Passando à análise da metafunção composicional, encontra-se enquadramento com recurso de moldura (framing) apenas no terceiro anúncio, o que pode ser explicado pela existência do processo conceitual analítico. Também, considerando que o anunciante Airbnb é uma empresa que viabiliza a hospedagem em casas de pessoas comuns, a imagem se compõe como um mosaico de seres humanos que se unem na sua individualidade. Diferentemente dos dois anúncios anteriores, as pessoas não se encontram unidas por um abraço, permanecem cada uma no seu próprio enquadramento, entretanto, se unem na composição.

Quanto à hierarquia, no primeiro anúncio não há propriamente uma hierarquia, pois os indivíduos estão todos representados no plano médio em posição semelhante e com uma distribuição de cores também equilibrada, já que houve o cuidado de colocar pessoas de pele clara e pele escura igualmente distribuídas. A única diferença encontrada é em relação à altura das pessoas, sendo que a dupla do centro é levemente mais baixa que os outros. No segundo anúncio, há uma hierarquia distinta: o homem está posicionado no centro da imagem, tem altura maior do que as outras participantes 
e abraça ambas na região do pescoço. Sua pele é diferente da delas pelo vitiligo, e apenas suas mãos e braços são visíveis na imagem, ou seja, as muIheres só aparecem dos ombros para cima. Ambas se inclinam em direção ao ator, a da esquerda volta seu olhar para o lado, em direção a ele, enquanto a da direita mantém o olhar no espectador da imagem mas inclina sua cabeça em direção ao ator. Já no terceiro anúncio há uma hierarquia principalmente pelo tamanho maior e pela posição central de uma das imagens, o rosto masculino formado por pelo menos duas faces diferentes. Os demais rostos variam em tamanho mas não em posição.

Em relação às cores, os três anúncios possuem diferentes tonalidades de bege e marrom, pois representam a diversidade das cores de pele. Isso ocorre pela intenção de simbolizar a união e a diversidade de seres humanos. A particularidade que se observa é que o anúncio da Benetton coloca essa diversidade sobre um grande contraste com o branco total do fundo. Bege e marrom são cores quentes e, assim, os anúncios aproximam imagem e espectador.

Segundo Kress e van Leeuwen (2006), o contato se estabelece com base na forma como participantes representados (que estão presentes na imagem) interpelam os participantes interativos (que fazem parte da interação social, por exemplo, o leitor de um anúncio). Nas três peças analisadas, há o direcionamento do olhar dos participantes representados diretamente para os participantes interativos, ou seja, os olhares se direcionam para o espectador, realizando contato do tipo demanda ou interpelação. A representação que foge desse padrão está no anúncio da Skol, em que uma das participantes representadas olha para o outro participante representado, o homem no centro da imagem.

Além do contato, na metafunção interativa há a distância social, que pode ser máxima ou mínima, dependendo do plano ou tipo de corte da imagem. No primeiro anúncio (Benetton), o corte está no plano médio, ou seja, todas as pessoas estão fotografadas da cintura para cima, aparentemente nuas em um plano conjunto. O plano conjunto auxilia a estabelecer o processo conceitual classificatório de taxonomia implícita. Por haver o plano médio, a distância social nesse caso não é máxima, nem mínima, é mediana. No segundo anúncio, a Skol utiliza o primeiro plano, isto é, o corte da linha dos ombros para cima, para reduzir a distância social, que nesse caso se torna mínima. Com isso, o anúncio busca aproximar o vínculo com o leitor.

Já no terceiro anúncio, o Airbnb interpela o espectador com distância 
social mínima por meio do close, em que o enquadramento mostra as pessoas do queixo até o topo da cabeça, além do plano detalhe, que mostra parte do rosto de algumas pessoas para compor os participantes representados. Dessa forma, o anunciante traduz na imagem o conceito de sua campanha, referente a romper barreiras entre pessoas de origens e culturas diferentes, fortalecendo a ideia presente na hashtag (\#weaccept): fazer parte do Airbnb é aceitar entrar na casa ou oferecê-la a diferentes pessoas.

A análise da perspectiva considerou o ângulo utilizado nas representações, o que pode ser frontal, oblíquo ou vertical (KRESS; VAN LEEUWEN, 2006). O anúncio de Benetton apresenta a imagem com ângulo oblíquo, pois todos estão representados lateralmente, ainda que façam contato com o espectador por meio do olhar. O anúncio da Skol apresenta ângulo frontal em dois participantes e oblíquo naquela modelo que volta seu rosto para o outro participante. Por sua vez, o Airbnb representa todos os rostos no ângulo frontal, reforçando novamente o sentido do anúncio.

$\mathrm{Na}$ análise do valor da informação, foram considerados os eixos horizontal e vertical das peças, com as estruturas de ideal e real e dado e novo de Kress e van Leeuwen (2006). As setas vermelhas mostram as estruturas encontradas (Figura 4):

Figura 4 - Valor da informação nas imagens (ideal e real, dado e novo).
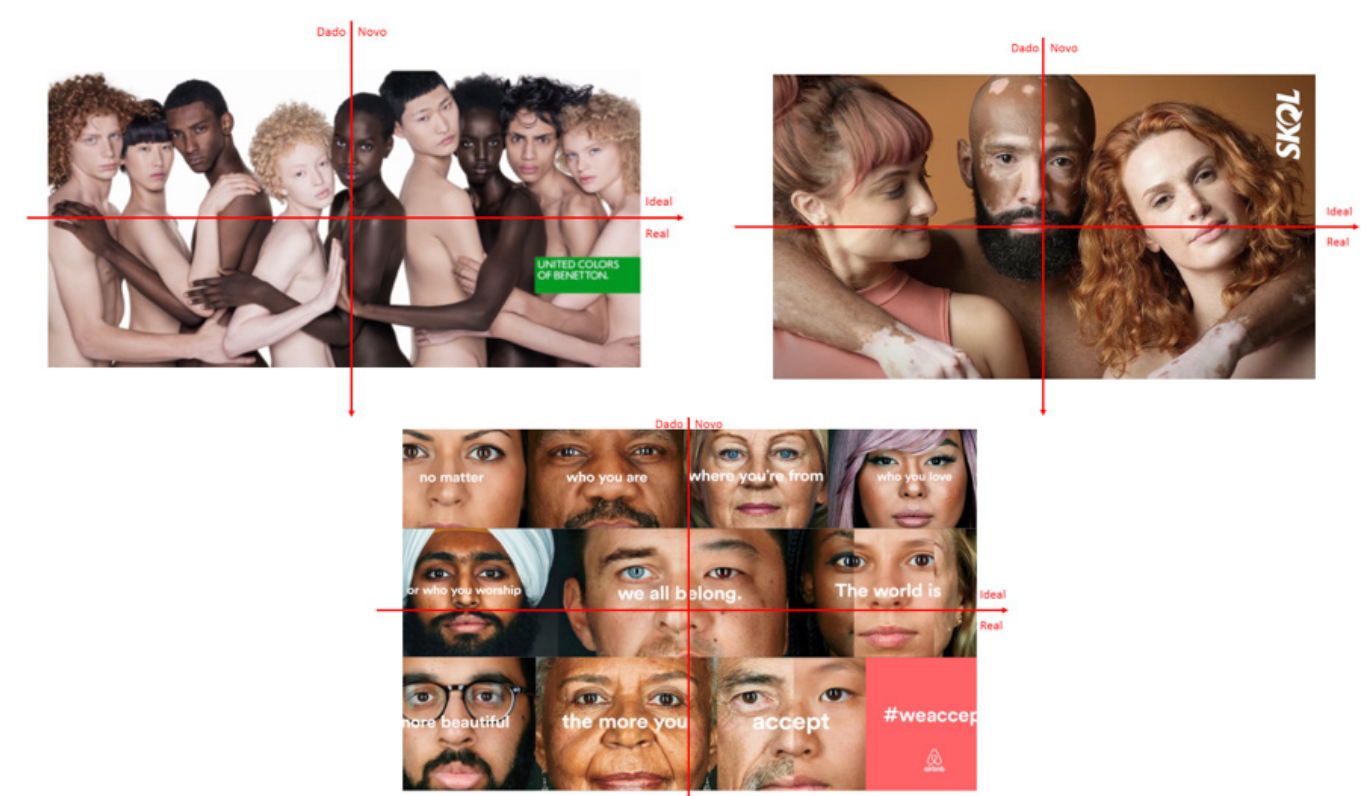

Fonte: Elaboração própria.

Assim, constata-se que o primeiro e o terceiro anúncio colocam logo e slogan dos anunciantes na posição do real, ou seja, como elemento concre- 
to da peça, enquanto o segundo anunciante assina a peça lateralmente na posição de ideal, como elemento idealizado. Considerando os participantes representados, o anúncio de Benetton mantém, na posição de ideal, cabeça e ombros de todos os modelos; o anúncio da Skol mantém na posição de ideal a maior parte do rosto dos seus modelos; já o anúncio de Airbnb distribui praticamente de forma equilibrada rostos no ideal e no real da peça.

Em relação à estrutura de dado e novo, a assinatura de todos os anunciantes está situada com o valor de novo, ou seja, é a informação já permanente dessas marcas sendo anunciada como nova. Na posição de dado prevalecem as imagens, sem particularidades observadas, já que as composições visuais estão predominantemente centralizadas nas telas ou páginas.

O caráter social da pesquisa possui grande relevância de forma a levar a assimilar construções de gênero que acabam afetando as práticas sociais, o que tem se materializado em anúncios publicitários. A marca Skol com a campanha intitulada "Skolors" procurou criar identificação quanto a diversidade do público consumidor de seu produto, alterando as cores das latas de cerveja aos tons da pele humana, enquanto, Benetton propõe uma união das diferenças perante a marca, nomeando a campanha de "United Colors Of Benetton". O Airbnb defende a aceitação das diferenças das pessoas ao passo que todas vivem no mesmo mundo. Esses três conceitos de campanha são constatados verbo-visualmente, sendo que as imagens possuem uma importância mais proeminente do que os textos verbais nas peças selecionadas. Os dados da análise confirmam que os três anunciantes tentam valorizar as diferenças entre as pessoas, diferenças centradas em gênero, cor da pele, etnia e faixa etária³.

Considerando o gênero social, o anúncio da Skol se destaca porque, a partir de um primeiro olhar busca valorizar a presença de duas figuras femininas em relação a uma masculina e, com base nas categorias analisadas acaba dando mais importância visual a figura masculina localizada no centro do anúncio que está em uma posição de poder ou de hierarquia superior, o que é reforçado pelo seus braços apoiados sobre os ombros das mulheres e pelo olhar contemplativo de uma delas. E essa diferença de gênero coexiste com uma valorização da diferença das cores de pele.

$\mathrm{Na}$ análise crítica do discurso, é importante captar o fio discursivo em

3 Com a ressalva de que representações de diferentes idades só estão bastante marcadas no terceiro anúncio de Airbnb. 
que se situam os discursos dessas marcas para a compreensão da dimensão social. Assim, recuperando discursos anteriores, o anúncio da Benetton, intitulado United Colors of Benetton, realiza uma atualização e, ao mesmo tempo, uma nova investida na estratégia inaugurada pela marca há mais de 50 anos atrás, com o mesmo slogan "Cores unidas da Benetton". A marca italiana de vestuário sediada em Nova York quis, desde o primeiro anúncio com esse conceito, utilizar imagens de inclusão e de diversidade de gênero, cor, etnia e características físicas, relacionando tal diversidade com as cores diversificadas e vibrantes de suas roupas. Nos anos 80, esse discurso de Oliviero Toscani foi considerado polêmico, pois fazia uso inclusive de pessoas com Síndrome de Down ou pessoas amputadas, raramente mostradas em qualquer campanha por critérios estereotipados de escolhas tradicionalmente realizadas pela publicidade. Com isso, desde o princípio, a marca Benetton se colocou a favor do rompimento de barreiras nas representações de seres humanos. Com o novo anúncio, considerando os discursos anteriores, percebe-se a preservação do culto à diversidade, porém, a estratégia visual adotada não é o uso de cores de roupas diferentes unidas na mesma fotografia, mas o uso de cores de peles diversificadas e a ausência de cores vibrantes.

Já a recuperação de discursos anteriores da marca Skol demonstra uma situação diferente, pois o histórico de campanhas da marca de cerveja inclui a forma mais arraigada de se fazer publicidade desse gênero de produto: mulheres eram representadas oferecendo cerveja ou sendo ofertadas juntamente com o produto, por uma exploração de corpos femininos nas imagens. Além disso, em 2015, ocorreu uma crise de imagem de marca quando foi veiculada uma campanha que, em sua interpretação pelo público, foi vista como um incentivo ao assédio no carnaval. Segundo o site UOL (2015), a campanha daquele ano, que fazia uso da chamada "Esqueci o Não em casa", foi considerada irresponsável pela maioria dos internautas que se manifestaram publicamente nas redes. Desse modo, o anúncio intitulado Skolors foi amplamente divulgado em mídias sociais porque foi nessas mídias que ocorreram manifestações recentes de consumidoras rechaçando o estereótipo machista utilizado pela marca anteriormente. Em certa medida, o anúncio atende ao propósito de enfatizar a diversidade de cores de pele. Por outro lado, acaba recorrendo a estruturas multimodais de contato, perspectiva, distância social e valor da informação que, uma vez descritos, demonstram diferenças e assimetrias de gênero social persistentes. 
O terceiro anúncio analisado, do Airbnb, intitulado \#weaccept, tem uma particularidade que favorece a liberdade de interpretação da peça porque, por se tratar de uma marca relativamente nova de serviços, seu histórico publicitário não é muito amplo. Sendo assim, há um emparelhamento de seu anúncio recente com a premissa de divulgação do próprio serviço: abrir as portas de sua casa para estrangeiros do mundo inteiro, em troca não só de compensação financeira, mas, principalmente, de experiências humanas e de viagens. Isso é declarado nas imagens de diversidade e por meio do slogan, com o uso da segunda pessoa plural ("nós") e o verbo "aceitamos". Realizando uma reflexão a respeito da construção sociocultural de gênero e diversidade na publicidade, a partir das teorias consultadas, cabe retomar um dos questionamentos propostos por Scott (1995): "Se as significações de gênero e de poder se constroem reciprocamente, como as coisas mudam? De um ponto de vista geral, a resposta é que a mudança pode ser iniciada em muitos lugares" (SCOTT, 1995, p. 92). Naquele momento, a autora propôs que um local propício para o rompimento das desigualdades socialmente estabelecidas era a política. Mas, para além da esfera política, têm-se testemunhado mudanças de discurso que ocorrem de fora para dentro das estruturas sociais mais rígidas ou institucionalizadas, ou seja, a partir das vozes múltiplas e diversas do público, outrora considerado mero receptor de mensagens.

Atualmente, sabe-se que a comunicação é dialógica e pressupõe a capacidade de resposta aos discursos circulantes, inclusive na mídia (BAKHTIN, 2010). E, nesse sentido, a publicidade como prática discursiva e social pode funcionar como um elemento de transformação ou, pelo menos, de inclusão das diferenças e do rompimento com construções hegemônicas ou estereotipadas. Conforme Scott (1995, p. 93) complementa, "a natureza desse processo, dos atores e de suas ações, só pode ser determinada de forma específica, no contexto do tempo e do espaço. Nós só podemos escrever a história desse processo se reconhecermos que "homem" e "mulher" são, ao mesmo tempo, categorias vazias e transbordantes". Sendo assim, a inclusão de questionamentos sobre as representações visuais diferenciadas para homens e mulheres ou sobre a raridade de discursos de diversidade humana é, em si, um rompimento, porque traz à luz construtos sociais e imagéticos que, por outro lado, poderiam já estar sedimentados no tecido social a ponto de passarem despercebidos. Assim como Scott (1995, p. 93) ressalta, é "a exploração dessas questões [que] fará emergir uma história que oferecerá 
novas perspectivas sobre velhas questões", ou seja, não se constroem novas práticas sem questionarmos velhas práticas".

Além disso, os anúncios exploram a noção de pertencimento a uma classe de seres humanos diversos e, nesse caso, é possível fazer o paralelo com a teoria de Lauretis (1994), segundo a qual o gênero como tecnologia de representação e auto-representação atribui a uma pessoa um status ou uma noção de pertencimento a uma classe de pessoas previamente construída. Essa construção ocorre há muito tempo na sociedade e, ultimamente, “continua a ocorrer não só onde se espera que aconteça - na mídia, nos tribunais, nas escolas públicas e particulares, na família nuclear, extensa ou monoparental (LAURETIS, 1994, p. 209). Para a subversão desses sistemas e ainda dentro da concepção de gênero, está a sua desconstrução como forma de construção, ou seja, desconstruir o que se entende por gênero já é em si uma nova forma de construção. Assim, a autora considera que há "novos espaços de discurso" ou "pontos-cegos", isto é, "espaços nas margens do discurso hegemônico" em que podem ser realocados novos significados associados ao gênero (LAURETIS,1994, p. 236), visando a novas compreensões das relações sociais.

\section{CONSIDERAÇÕES FINAIS}

Este trabalho propôs-se a analisar anúncios publicitários com base na teoria da multimodalidade de Kress e van Leeuwen (2006), a partir de anúncios com aparente diversidade de identidade e gênero social de três anunciantes de segmentos diferentes de produtos e serviços. Os resultados da análise permitem concluir que os três anunciantes possuem recorrências na forma de elaborar seus discursos da diversidade, que são: todos possuem representações humanas com diferenças de gênero, cor da pele, etnia e idade; o processo conceitual classificatório é predominante, sendo que o sentido de classe refere-se a união de diferentes seres humanos; nas cores predominam tons de bege e marrom para enfatizar o significado da diversidade de cores de pele; todos os anúncios contém imagem de demanda, que interpelam diretamente o leitor por meio do olhar; apresentam ângulo oblíquo ou frontal nas imagens; colocam a assinatura dos anunciantes como elemento novo.

Quando se menciona a análise do discurso, a tendência é valorizar o texto verbal, entretanto o que este trabalho demonstra é que as imagens significam tanto quanto o texto verbal e tornam-se proeminentes no caso das 
três peças analisadas, que possuem texto verbal mínimo ou bastante curto em relação à riqueza e ao detalhamento das imagens. Nesse sentido, as ferramentas de análise fornecidas pela gramática de Kress e van Leeuwen (2006) foram essenciais para averiguar se os sentidos que se compreendem das peças em uma leitura primária coincidem ou divergem com os dados observados na leitura analítica. Destaca-se, nesse caso, a análise do anúncio da Skol, em que persistem hierarquia e, portanto, assimetrias de gênero, ainda que seu discurso valorize a diversidade das cores de pele. No anúncio da Benetton, destaca-se que a união de cores afirmada no seu slogan (United colors of Benetton) se materializa visualmente na união de mãos, braços e corpos. Já o anúncio do Airbnb, ainda que seja o único que utiliza o recurso de moldura (framing), em vez de compartimentar as pessoas em diferentes quadros, acaba unindo todas elas na composição do mosaico visual e, com o uso do close e do plano detalhe destaca-se como o anúncio com menos distância social dos três analisados.

A análise crítica do discurso no modelo de Fairclough (2001) enfatiza a importância da análise integrada ao contexto social e, por isso, foram recuperados sentidos produzidos em discursos anteriores presentes no histórico de cada marca. É esse viés de análise que possibilita considerar, também, o discurso como prática social que não só reproduz discursos já ditos ou estereótipos frequentemente encontrados na publicidade. Contrariando o senso comum, a publicidade pode investir no rompimento de construções identitárias estereotipadas e preconceituosas, e a análise demonstrou três casos que exemplificam esse rompimento e a realização do discurso como elemento de transformação ou, em um primeiro momento, como um índice sensível das mudanças sociais que são, cada vez mais, valorizadas e exigidas por consumidoras e consumidores.

\section{REFERÊNCIAS}

BOURDIEU, P. A dominação masculina. $4^{\mathrm{a}}$ ed. Rio de janeiro: Bertrand Brasil, 2005.

CALDAS-COULTHARD, C. R.; van LEEUWEN, T. Discurso crítico e gênero no mundo infantil: brinquedos e a representação de atores sociais. Linguagem em (Dis)curso - LemD, Tubarão, v. 4, n.esp, p. 11-33, 2004.

COLLING, A. A construção da história do feminino e do masculino. In: STREY, M. N.; CABEDA, S. T. L.; PREHN, D. R. (orgs.) Gênero e cultura: questões contemporâneas. Porto Alegre, RS: EDIPUCRS, 2004.

ESCALATE Digital Marketing. Best social media campaigns 2017. Disponível em: https:// escalate.ie/best-social-media-campaigns-of-2017/. Acesso em: 20 set. 2018. 
FAIRCLOUGH, N. Discurso e mudança social. Brasília: UnB, 2001.

GHILARDI-LUCENA, M. I. As representações do feminino na publicidade. In: GHILARDI-LUCENA, M. I. (Org.). Representações do feminino. São Paulo: Átomo, 2003. p. 159-178.

HALL, S. A identidade cultural na pós-modernidade. 9. ed. Rio de Janeiro: DP\&A, 1999.

Halliday, M. A. K. An introduction to Functional Grammar. London: Edward Arnold, 1985. KNOLL, G. F. Relações dialógicas entre gênero social, discurso e mídia na análise da publicidade. SCRIPTA, Belo Horizonte, v. 22, n. 45, p. 81-96, 2018.

KRESS, G.; van LEEUWEN, T. Reading Imagens: the grammar of visual design. 2. ed. London: Routledge, 2006.

O SUL. Skol comemora fim do verão sem estereótipos com um brinde ao respeito. Disponível em: http://www.osul.com.br/skol-comemora-fim-verao-sem-estereotipos-com-um-brinde-ao-respeito-2/. Acesso em: 20 set. 2018.

SCOTT, J. 1995. Gênero: uma categoria útil de análise histórica. Educação e Realidade, Porto Alegre, v. 2, n. 20, p. 73-99, jul/dez. 1995.

SBD. Sociedade Brasileira de Dermatologia. Vitiligo. 2018. Disponível em: http://www.sbd. org.br/dermatologia/pele/doencas-e-problemas/vitiligo/21/. Acesso em: 13/12/2018.

TREVISOTODAY. "Nudi come", la nuova campagna Benetton firmata da Oliviero Toscani. Disponível em: http://www.trevisotoday.it/blog/benetton-toscani-nudi-campagna-2-agosto-2018.html. Acesso em: 20 set. 2018.

VESTERGAARD, T.; SCHRØDER, K. A linguagem da propaganda. 3. ed. São Paulo: Martins Fontes, 2010.

UOL. Anúncio da Skol gera polêmica. 02/11/2015. Disponível em: https://economia.uol. com.br/noticias/redacao/2015/02/11/anuncio-da-skol-para-o-carnaval-gera-polemica-peca-incentivaria-assedio.htm. Acesso em: 20 set. 2018.

WODAK, R. Do que trata a ACD - um resumo de sua história, conceitos importantes e seus desenvolvimentos. Linguagem em (Dis)curso - LemD, Tubarão, v. 4, n.esp, p. 223$243,2004$. 


\section{Graziela Frainer Knoll}

Professora na Universidade Franciscana, nos cursos de Publicidade e Propaganda e Jogos Digitais; Doutora em Letras - Estudos Linguísticos (UFSM); Mestra em Letras - Estudos Linguísticos (UFSM); Especialista em TIC Aplicadas à Educação (UFSM); Bacharel em Publicidade e Propaganda (UFSM); Licenciada em Letras - Língua Portuguesa e Literaturas (UFSM), com pós-doutorado no Centro Universitário Ritter dos Reis (UniRITTER, Porto Alegre, RS). gênero. E-mail: grazi.fknoll@gmail.com

\section{Liane dos Santos Vellozo}

Acadêmica do sétimo semestre do curso de Publicidade e Propaganda da Universidade Franciscana e atua como pesquisadora de iniciação científica, bolsista PROBIC/UFN, atua em projeto de pesquisa vinculado a este trabalho. gênero. E-mail: lianesvellozo@gmail.com 